\title{
Intervention program to promote self-management for prevention of lymphedema after gynecological cancer surgery - Evaluation of the effectiveness at 12 months after the intervention -
}

\author{
Mayumi SATO \\ Department of Nursing, Faculty of Health \& Medical Care \\ Saitama Medical University \\ Saitama, Japan \\ ma_sato@saitama-med.ac.jp
}

\author{
Chiaki KINOUCHI \\ Department of Nursing, Faculty of Nursing \\ Iwate University of Health and Medical Sciences \\ Iwate, Japan \\ kinouchi@iwate-uhms.ac.jp
}

\begin{abstract}
In Japan cancer has been the most common cause of deaths since 1981, and effort has been made to provide countermeasure for cancers. The key to countermeasures is for the general population including cancer patients to know about and overcome cancer. Because the development of cancer is related to lifestyle, it is necessary to work at preventing cancer with attention to the conduct of daily life. The five-year relative survival rate registered in the community from 2006 to 2008 was $62.1 \%$, and this illustrates that there are many cancer survivors leading daily lives after contracting cancer. Uterine cancer was the fifth most common in cancer in 2013. However, it is an important object of the treatment to prevent postoperative complications in gynecologic cancer patients, such as development of lymphedema, because it is reported that the survival rate of uterine cancer is high. The incidence of lymphedema is reported to be between $27.2 \%$ and $42 \%$ in Japan. Once lymphedema develops, it is difficult to cure, making prevention of the onset an important issue.
\end{abstract}

As a result of the multiple logistic regression analysis performed here using patients where the right femoral circumference increased $2 \mathrm{~cm}$ or more as an objective variable, there were differences between the groups analyzed (intervention and control). Compared to the intervention group, 4.46 times more patients in the control group had increases in the right femoral circumference by $2 \mathrm{~cm}$ or more. We conducted a randomized controlled trial of an intervention program to promote self-management to prevent lymphedema development after gynecological cancer surgery, and examined the effectiveness at 12 months after the surgery. From the results it can be inferred that observing the lymphedema symptoms including measuring and recording of femoral circumferences and body weight by patients themselves influenced the promotion of self-management. Six months after the surgery, there were significantly more patients who developed lymphedema in the control group, but there were no differences between the groups at 12 months after the surgery. Lymphedema development after gynecological cancer surgery appears about 2.6 months after surgery and chronic lymphedema often appears around 9.7 months after surgery. It can be inferred that this difference is due to the temporary improvement of lymphatic reflux after the improvement of edema. The difference in femoral circumferences is sometimes used as one diagnostic tool for the determination of lymphedema. In this study, we compared the right femoral circumferences before discharge and 12 months after the surgery. Mild lymphedema is defined as larger than $10 \mathrm{~mm}$ but smaller than $20 \mathrm{~mm}$ in any dimension. In severe cases, a dimension may be larger than $20 \mathrm{~mm}$ ]. In this study, we performed a multiple logistic regression analysis by defining the patients with lymphedema as patients whose right femoral circumference is increased more than $2 \mathrm{~cm}$. The analysis showed the following as factors influencing the increase in the right femoral circumference by more than $2 \mathrm{~cm}$ : group (intervention and control), aerobic exercise, and self-efficacy. Compared to the intervention group, 4.46 times more patients in the control group had increases in the right femoral circumference of more than 2 $\mathrm{cm}$, and this suggests that the intervention program to promote self-management to prevent lymphedema after gynecological cancer surgery is effective at $\mathbf{1 2}$ months after the surgery.

Keywords; gynecological cancer; lymphedema; selfmanagement; intervention programs

\section{INTRODUCTION}

In Japan cancer has been the most common cause of deaths since 1981 [1], and effort has been made to provide countermeasure for cancers. The key to countermeasures is for the general population including cancer patients to know about and overcome cancer [2]. Because the development of cancer is related to lifestyle, it is necessary to work at preventing cancer with attention to the conduct of daily life [3]. The five-year relative survival rate registered in the community from 2006 to 2008 was $62.1 \%$ [4], and this illustrates that there are many cancer survivors leading daily lives after contracting cancer. Uterine cancer was the fifth most common in cancer in 2013. However, it is an important object of the treatment to prevent postoperative complications in gynecologic cancer patients, such as development of lymphedema, because it is reported that the survival rate of uterine cancer is high [4].

Patients who undergo lymph node dissection are classified as at Stage 0 of the lymphedema classification (International Society of Lymphology) [5-7]. No clinical symptoms appear at 
this stage, but there is a lymphatic transport disorder. In many cases this condition appears temporarily, but some cases lead to chronic edema. The incidence of lymphedema is reported to be between $27.2 \%$ [8] and 42\% [9] in Japan. As there are no established diagnostic criteria for gynecological cancer postoperative lymphedema, and it is difficult to determine an accurate incidence rate [10]. Once lymphedema has developed, it is difficult to cure, so preventing the onset is an important issue. Because lymphedema may develop decades after surgery, it is essential to continue with lymphedema prevention measures that can be conducted for long periods. Further, as the length of hospitalization has been shortened, there are numerous patients who have to be discharged without sufficient knowledge and skills to prevent lymphedema [10].

Self-management is defined as the effort of clients (patients) to learn the knowledge and skills unique to their own disease and the medical treatment while dealing with symptoms and signs in their everyday life [11,12]. Patients with gynecological cancer need to continue self-management because they need to deal with complications and adverse effects arising from the disease and treatment as it is the case for patients with chronic diseases. We have not located any intervention program to promote self-management as a preventive measure for lymphedema after gynecological cancer surgery. For this reason, we developed an intervention program to promote self-management to prevent lymphedema after gynecological cancer surgery, and conducted a randomized controlled trial of the effect of the program. Six months after the intervention and surgery, the incidence of lymphedema in the intervention group was significantly lower than in the control group [9][13]. As a result of the multiple logistic regression analysis using the presence or absence of lymphedema as an objective variable, coping with symptoms by patients themselves as well as the intervention effect were found to be factors influencing the increase in the right femoral circumference [9][13]. In this study we examine the effectiveness of the intervention program at 12 months after the implementation, and improved the effectiveness of the program to promote self-management to prevent lymphedema after gynecological cancer surgery.

\section{PURPOSE}

We will implement an intervention program to promote self-management to prevent lymphedema from occurring in female cancer patients after surgery to establish the effect of intervention after 12 months.

\section{METHODS}

\section{A. Participants and procedures}

The study participants were gynecologic cancer patients who had undergone lymph node dissection in the five participating hospitals in the Kanto region of Japan. Participant inclusion criteria are patients aged between 20 and 74, who are able to conduct self-management, participate in all the programs for one year, and who are evaluated to be in stable physical and mental conditions. We explained the outline of the study to 130 patients, and 108 expressed consent to participate.

\section{B. Program}

\section{1) The intervention group}

Before discharge, we explained about self-management to prevent lymphedema using a booklet. After the discharge, we provided patients with health instruction once a month for 6 months by phone. The femoral circumference and body weight were measured and recorded weekly up to 6 months from the time when patients were still hospitalized, and at 12 months after surgery.

\section{2) The control group}

The femoral circumference and weight were measured and recorded before discharge and at the $6^{\text {th }}$ and $12^{\text {th }}$ months after surgery.

\section{Survey period and other details}

(1) The survey was administered from August 1, 2012 to August 31, 2015.

2) The right and left femoral circumferences and body weight, and presence of lymphedema were surveyed. For the self-rating questionnaire, we used a modified Japanese version of the Chronic Disease Self-Management Program (CDSMP) [14].

The questionnaire contains questions about demographic characteristics: hospital name, date of birth, academic background, presence of spouse (partner), presence of other persons living together in the household, employment, living circumstances, economic conditions, whether being well off (health), presence of unusual events and/or conditions, smoking, names of diseases, and types of surgery; health conditions: worries about health, and other symptoms, selfevaluation of health conditions, stress coping skills (SOC) [15], and WHO QOL-26, self-efficacy with health problems; and self-management behaviors: durations of doing aerobic exercises, mental health (anxiety / depression), relationship with medical personnel, and coping with symptoms.

\section{Statistical analysis}

Data from the measurements before discharge and at 12 months after surgery for the two groups were compared. We used the significance level $<0.05$ for establishing statistical differences. For the statistical analysis we used the SPSS for windows ver. 25 .

\section{E. Reward}

We handed out a gift coupon for books (valued at 1500) to participants who returned the questionnaire.

\section{F. Ethical considerations}

Complying with ethical guidelines we ensured the protection of human rights. We stated that participants have a right to withdraw from the study even after expressing consent. We obtained approval from the Ethics Committee of the International University of Health and Welfare, Japan (No. 1216), and from the ethics committees of the participating hospitals. We also used rooms where the privacy of the participants can be protected, and paid careful attention to 
Table 1 Demographic characteristics of participants $1(N=97)$

\begin{tabular}{|c|c|c|c|c|c|c|}
\hline \multirow[t]{2}{*}{ Item } & \multirow[t]{2}{*}{ Small item } & \multicolumn{2}{|c|}{ Intervention $(\mathrm{n}=52)$} & \multicolumn{2}{|c|}{ Control $(n=45)$} & \multirow[t]{2}{*}{$\mathrm{P}$} \\
\hline & & Number & $(\%)$ & Number & $(\%)$ & \\
\hline \multirow[t]{2}{*}{ Hospital location } & Non-urban & 34 & 66.7 & 30 & 66.7 & \\
\hline & Urban & 17 & 33.3 & 15 & 33.3 & \\
\hline \multirow[t]{2}{*}{ Types of surgery } & Pelvic lymph node dissection & 32 & 62.7 & 33 & 73.3 & \\
\hline & Para-aortic lymph node dissection & 19 & 37.3 & 12 & 26.7 & \\
\hline \multirow[t]{2}{*}{ Spouse (partner) } & No & 12 & 23.5 & 4 & 8.9 & \\
\hline & Yes & 39 & 76.5 & 41 & 91.1 & \\
\hline \multirow[t]{2}{*}{ Persons living together } & No & 5 & 9.8 & 4 & 8.9 & \\
\hline & Yes & 46 & 90.2 & 41 & 91.1 & \\
\hline \multirow[t]{2}{*}{ Employment } & No & 15 & 29.4 & 24 & 53.3 & \\
\hline & Yes & 36 & 70.6 & 21 & 46.7 & $*$ \\
\hline \multirow[t]{2}{*}{$\begin{array}{l}\text { Ease in economic } \\
\text { condition }\end{array}$} & No & 30 & 58.8 & 20 & 44.4 & \\
\hline & Yes & 21 & 41.2 & 25 & 55.6 & \\
\hline \multirow[t]{2}{*}{$\begin{array}{l}\text { Unusual } \\
\text { events/conditions }\end{array}$} & No & 21 & 41.2 & 18 & 40 & \\
\hline & Yes & 30 & 58.8 & 27 & 60 & \\
\hline \multirow[t]{2}{*}{ Smoking } & No & 45 & 88.2 & 42 & 93.3 & \\
\hline & Yes & 6 & 11.8 & 3 & 6.7 & \\
\hline \multirow[t]{2}{*}{ Names of diseases } & Uterine cancer & 42 & 82.4 & 42 & 93.3 & \\
\hline & Ovarian cancer & 9 & 17.6 & 3 & 6.7 & \\
\hline
\end{tabular}

minimize the mental and physical burden on these patients, ensuring that mental and physical distress would not increase.

\section{RESULTS}

We explained the outline of the study to 130 patients, and 108 expressed consent. We randomly divided the patients into two groups: 56 as an intervention group, and 52 as a control group. Before the discharge, 52 valid responses $(92.8 \%)$ to the questionnaire were collected from the intervention group and $45(86.5 \%)$ from the control group, and at 12 months after surgery, from $48(92.0 \%)$ of the intervention group, and from $40(88.3 \%)$ of the control group. Responses that included unanswered questions and incomplete responses were excluded from the analysis.

\section{A. Demographic characteristics of participants}

The ratio of the participants who were in employment was significantly higher in the intervention group, but the groups had no significant differences in any of the other demographic details (other than employment) (Table 1).

\section{B. Body measurements}

\section{1) Before discharge}

There were also no significant differences in the femoral circumference, body weight, presence or absence of lymphedema between the two groups (Table 2 through 4).

2) At 12 months after surgery

The right and left femoral circumferences and body weight were significantly smaller in the intervention group, but there was no difference in the incidence of lymphedema in the groups (Tables 5 and 6).

\section{Table 2 Demographic characteristics of participants $2(\mathrm{~N}=97)$}

\begin{tabular}{|c|c|c|c|c|c|c|c|c|c|c|c|}
\hline \multirow[t]{2}{*}{ Item } & \multicolumn{2}{|c|}{ Intervention $(\mathrm{n}=52)$} & \multirow{2}{*}{$\begin{array}{c}\text { Difference } \\
\text { in means }\end{array}$} & \multicolumn{2}{|c|}{ 95\% CI (Difference) } & \multicolumn{2}{|c|}{ Control $(n=45)$} & \multirow{2}{*}{$\begin{array}{c}\text { Difference } \\
\text { in means }\end{array}$} & \multicolumn{2}{|c|}{ 95\% CI (Difference) } & \multirow[t]{2}{*}{ P } \\
\hline & Mean & SD & & Lower & Upper & Mean & SD & & Lower & Upper & \\
\hline $\begin{array}{l}\text { Age } \\
\text { (years old) }\end{array}$ & 52.8 & 9.71 & 0.6 & 50.12 & 55.46 & 53.4 & 12.2 & 1.82 & 49.78 & 57.11 & \\
\hline $\begin{array}{l}\text { Schooling } \\
\text { (years) }\end{array}$ & 13.8 & 1.82 & -0.57 & 13.37 & 14.36 & 13.29 & 2.18 & 0.06 & 12.65 & 13.93 & \\
\hline
\end{tabular}




\begin{tabular}{|c|c|c|c|c|c|c|c|c|c|c|}
\hline \multirow[t]{2}{*}{ Item } & \multirow[t]{2}{*}{ Small item } & \multicolumn{2}{|c|}{ Intervention $(\mathrm{n}=52)$} & \multirow{2}{*}{$\begin{array}{c}\text { Difference in } \\
\text { means }\end{array}$} & \multicolumn{2}{|c|}{ Control $(n=45)$} & \multirow{2}{*}{$\begin{array}{c}\text { Difference in } \\
\text { means }\end{array}$} & \multicolumn{2}{|c|}{ 95\% CI (Difference) } & $\mathrm{P}$ \\
\hline & & Mean & $\mathrm{SD}$ & & Mean & SD & & Lower & Upper & \\
\hline \multirow{2}{*}{$\begin{array}{l}\text { Femoral } \\
\text { circumference }(\mathrm{cm})\end{array}$} & Right & 51.75 & 4.43 & 0.8 & 52.5 & 4.74 & 0.71 & -2.64 & 1.05 & \\
\hline & Left & 51.59 & 4.29 & 0.64 & 52.17 & 4.93 & 0.74 & -2.5 & 1.21 & \\
\hline $\begin{array}{l}\text { Body weight } \\
(\mathrm{Kg})\end{array}$ & & 54.65 & 8.52 & 3.82 & 58.31 & 10.11 & 1.51 & -7.58 & -0.07 & \\
\hline
\end{tabular}

$* \mathrm{p}<0.05, * * \mathrm{p}<0.01, * * * \mathrm{p}<0.001$

Independent Samples T-Test, SD: Standard deviation, CI: Confidence interval, If there is a missing value, it differs from the total number

Table 4 Presence of lymphedema - comparisons between groups before discharge ( $N=97)$

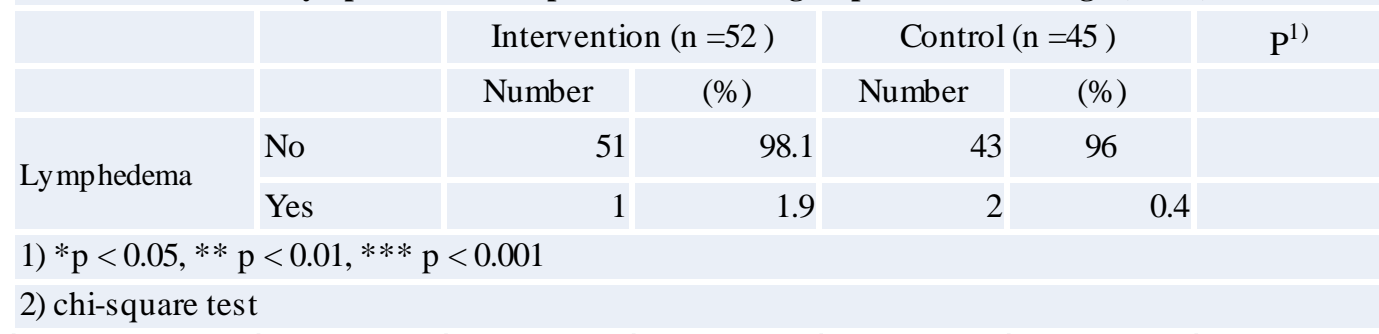

\begin{tabular}{|c|c|c|c|c|c|c|c|c|c|c|c|c|}
\hline \multicolumn{13}{|c|}{ Table 5 Physical measurements 1year after surgery $(\mathrm{N}=88$ ) } \\
\hline \multirow[t]{2}{*}{ Item } & \multirow[t]{2}{*}{ Small item } & \multicolumn{2}{|c|}{ Intervention $(\mathrm{n}=48)$} & \multirow{2}{*}{$\begin{array}{l}\text { Difference in } \\
\text { means }\end{array}$} & \multicolumn{2}{|c|}{$\begin{array}{c}95 \% \mathrm{CI} \\
\text { (Difference) }\end{array}$} & \multicolumn{2}{|c|}{ Control $(\mathrm{n}=40)$} & \multirow{2}{*}{$\begin{array}{c}\text { Difference in } \\
\text { means }\end{array}$} & \multicolumn{2}{|c|}{ 95\% CI (Difference) } & \multirow[t]{2}{*}{$\mathrm{P}$} \\
\hline & & Mean & SD & & Lower & Upper & Mean & SD & & Lower & Upper & \\
\hline \multirow{2}{*}{$\begin{array}{l}\text { Femoral circumference } \\
(\mathrm{cm})\end{array}$} & Right & 51.21 & 5.21 & 0.78 & 49.64 & 52.78 & 54.01 & 5.34 & 0.87 & 52.25 & 55.76 & * \\
\hline & Left & 51.37 & 4.75 & 0.71 & 49.94 & 52.81 & 53.52 & 5.44 & 0.9 & 51.73 & 55.31 & * \\
\hline Body weight $(\mathrm{Kg})$ & & 36.51 & 9 & 1.35 & 52.07 & 57.07 & 72.67 & 78.58 & 12.75 & 46.83 & 98.5 & * \\
\hline \multicolumn{13}{|c|}{$* \mathrm{p}<0.05, * * \mathrm{p}<0.01, * * * \mathrm{p}<0.001$} \\
\hline
\end{tabular}

\section{Mental and physical health conditions}

\section{1) Before discharge}

There were no significant differences in severity of symptoms, meaningfulness of sense of coherence (SOC), overall quality of life (QOL), physical area of QOL, or selfefficacy with health problems in the responses in the questionnaires (Table7).

\section{2) 12 months after surgery}

For the self-management behavior, the intervention group showed significantly higher scores in the interactions with medical personnel and in coping with symptoms (Table 8).

D. Multiple logistic regression analysis of participants who reported an increase in the right femoral circumference larger than $2 \mathrm{~cm}$ as the objective variable

Prior to the analysis we compared the demographic characteristics, health conditions, self-efficacy, and selfmanagement behaviors with those before discharge for the intervention and control groups to determine factors other than the effect of intervention that could have influenced the increase in the right femoral circumference of more than $2 \mathrm{~cm}$. After the comparison, we performed a multiple logistic regression analysis using participants who reported the increase in the right femoral circumference of more than $2 \mathrm{~cm}$ as an objective variable, and the demographic characteristics, health conditions, self-efficacy, and self-management behaviors as explanatory variables. Prior to the analysis we examined scatter charts and confirmed that there were no variables showing a remarkably linear relationship. After that, using the participants who had increases in the right femoral circumference of more than $2 \mathrm{~cm}$ as the objective variable, we performed the logistic regression (Forward Selection, Likelihood Ratio).

\begin{tabular}{|c|c|c|c|c|c|c|}
\hline & & \multicolumn{2}{|c|}{ Intervention $(\mathrm{n}=48)$} & \multicolumn{2}{|c|}{ Control $(n=40)$} & $\mathrm{P}^{1)}$ \\
\hline & & Number & $(\%)$ & Number & $(\%)$ & \\
\hline \multirow{2}{*}{ Lymphedema } & No & 34 & 70.8 & 32 & 80 & \\
\hline & Yes & 14 & 29.2 & 8 & 20 & \\
\hline
\end{tabular}


Table 7 Comparisons between groups before discharge $(N=97)$

\begin{tabular}{|c|c|c|c|c|c|c|c|c|c|c|c|c|}
\hline \multirow[t]{2}{*}{ Large item } & \multirow[t]{2}{*}{ Small item } & \multicolumn{2}{|c|}{ Intervention $(\mathrm{n}=52)$} & \multirow{2}{*}{$\begin{array}{l}\text { Difference in } \\
\text { means }\end{array}$} & \multicolumn{2}{|c|}{ 95\% CI (Difference) } & \multicolumn{2}{|c|}{ Control $(n=45)$} & \multirow{2}{*}{$\begin{array}{l}\text { Difference in } \\
\text { means }\end{array}$} & \multicolumn{2}{|c|}{ 95\% CI (Difference) } & \multirow[t]{2}{*}{$\mathrm{P}^{1)}$} \\
\hline & & Mean & SD & & Lower & Upper & Mean & SD & & Lower & Upper & \\
\hline \multirow[t]{12}{*}{$\begin{array}{l}\text { Health } \\
\text { conditions }\end{array}$} & $\begin{array}{l}\text { Worries about health } \\
\text { (range 1-5) }\end{array}$ & 2.09 & 1.27 & 1.78 & 1.73 & 2.45 & 2.09 & 1.33 & 0.2 & 1.69 & 2.5 & \\
\hline & Symptoms ${ }^{3)}$ (range 1-10) & 6.16 & 2.71 & 0.38 & 5.4 & 6.92 & 5.91 & 3.13 & 0.33 & 4.97 & 6.85 & \\
\hline & $\begin{array}{l}\text { Self-evaluation of health } \\
\text { conditions }^{3)} \text { (range 1-5) }\end{array}$ & 4.83 & 1.84 & 0.26 & 4.31 & 5.34 & 5.06 & 2.15 & 0.33 & 4.41 & 5.71 & \\
\hline & $\operatorname{SOC}^{4)}($ range 1-7) & 51.61 & 9.9 & 1.38 & 48.83 & 54.4 & 52.69 & 11.42 & 1.7 & 49.26 & 56.12 & \\
\hline & $\begin{array}{l}\text { SOC comprehensibility }{ }^{4)} \\
\text { (range 1-7) }\end{array}$ & 23 & 0.75 & 5.33 & 21.44 & 24.44 & 24.09 & 5.76 & 0.86 & 22.36 & 25.9 & \\
\hline & $\begin{array}{l}\text { SOC manageability }{ }^{4)} \\
\text { (range 1-7) }\end{array}$ & 19 & 4.1 & 0.57 & 17.85 & 20.15 & 19.62 & 4.6 & 0.69 & 18.24 & 21.01 & \\
\hline & $\begin{array}{l}\text { SOC meaningfulness } \\
\text { (range 1-7) }\end{array}$ & 20.22 & 4.58 & 0.64 & 18.93 & 21.5 & 19.62 & 4.62 & 0.69 & 18.23 & 21.01 & \\
\hline & $\mathrm{QOL}^{4}$ (range 1-5) & 3.23 & 0.47 & 0.66 & 3.1 & 3.37 & 3.2 & 0.5 & 0.07 & 3.05 & 3.35 & \\
\hline & QOL physical $^{54)}$ (range 1-5) & 2.96 & 0.56 & 0.78 & 2.8 & 3.11 & 3.02 & 0.47 & 0.07 & 2.88 & 3.16 & \\
\hline & QOL mental $^{4}$ (range 1-5) & 3.2 & 0.72 & 0.1 & 3 & 3.4 & 3.15 & 0.62 & 0.1 & 2.97 & 3.34 & \\
\hline & $\begin{array}{l}\text { QOL environmental }{ }^{4)} \\
\text { (range 1-5) }\end{array}$ & 3.44 & 0.55 & 0.08 & 3.28 & 3.6 & 3.39 & 0.61 & 0.1 & 3.2 & 3.56 & \\
\hline & $\begin{array}{l}\left.\text { QOL social relations }{ }^{4}\right) \\
\text { (range 1-5) }\end{array}$ & 3.69 & 0.53 & 0.07 & 3.54 & 3.84 & 3.55 & 0.69 & 0.1 & 3.34 & 3.75 & \\
\hline $\begin{array}{l}\text { Self-efficacy with } \\
\text { health problems }\end{array}$ & Self-efficacy ${ }^{4}$ (range $0-7$ ) & 4.83 & 1.84 & 0.26 & 4.31 & 5.34 & 5.06 & 2.15 & 0.32 & 4.42 & 5.71 & \\
\hline \multirow[t]{6}{*}{ Self-management } & $\begin{array}{l}\left.\text { Aerobic exercises }{ }^{4}\right) \\
(\text { range } 0-180)\end{array}$ & 28 & 45.69 & 6.4 & 15.11 & 40.81 & 41.71 & 55.1 & 8.21 & 25.17 & 58.26 & \\
\hline & Mental health ${ }^{4)}($ range $0-42$ ) & 27.61 & 6.52 & 0.91 & 25.77 & 29.44 & 26.76 & 6.06 & 0.99 & 24.96 & 28.55 & \\
\hline & $\begin{array}{l}\text { Subscale of mental health, } \\
\text { anxiety }^{4} \text { (range } 0-21 \text { ) }\end{array}$ & 13.31 & 4.15 & 0.58 & 12.15 & 14.48 & 14.42 & 4.08 & 0.69 & 13.2 & 15.65 & \\
\hline & $\begin{array}{l}\text { Subscale of mental health, } \\
\text { depression }{ }^{4}(\text { range } 0-21)\end{array}$ & 14.27 & 3.28 & 0.46 & 13.35 & 15.2 & 14.22 & 3.21 & 0.48 & 13.26 & 15.19 & \\
\hline & $\begin{array}{l}\text { Relationship with } \\
\text { physicians }{ }^{4}(\text { range } 0-5)\end{array}$ & 1.74 & 1.71 & 0.16 & 1.41 & 2.07 & 1.5 & 1.08 & 0.16 & 1.18 & 1.82 & \\
\hline & $\begin{array}{l}\left.\text { Coping with symptoms }{ }^{4}\right) \\
\text { (range } 0-5 \text { ) }\end{array}$ & 1.31 & 1.01 & 0.14 & 1.03 & 1.6 & 1.44 & 1.14 & 0.17 & 1.1 & 1.78 & \\
\hline \multicolumn{13}{|c|}{ 1) $* \mathrm{p}<0.05, * * \mathrm{p}<0.01, * * * \mathrm{p}<0.001$} \\
\hline \multicolumn{13}{|c|}{ 2) Independent Samples T-Test } \\
\hline \multicolumn{13}{|c|}{ 3) Lower scores show better conditions } \\
\hline 4) Higher scores sl & how better conditions & & & & & & & & & & & \\
\hline
\end{tabular}




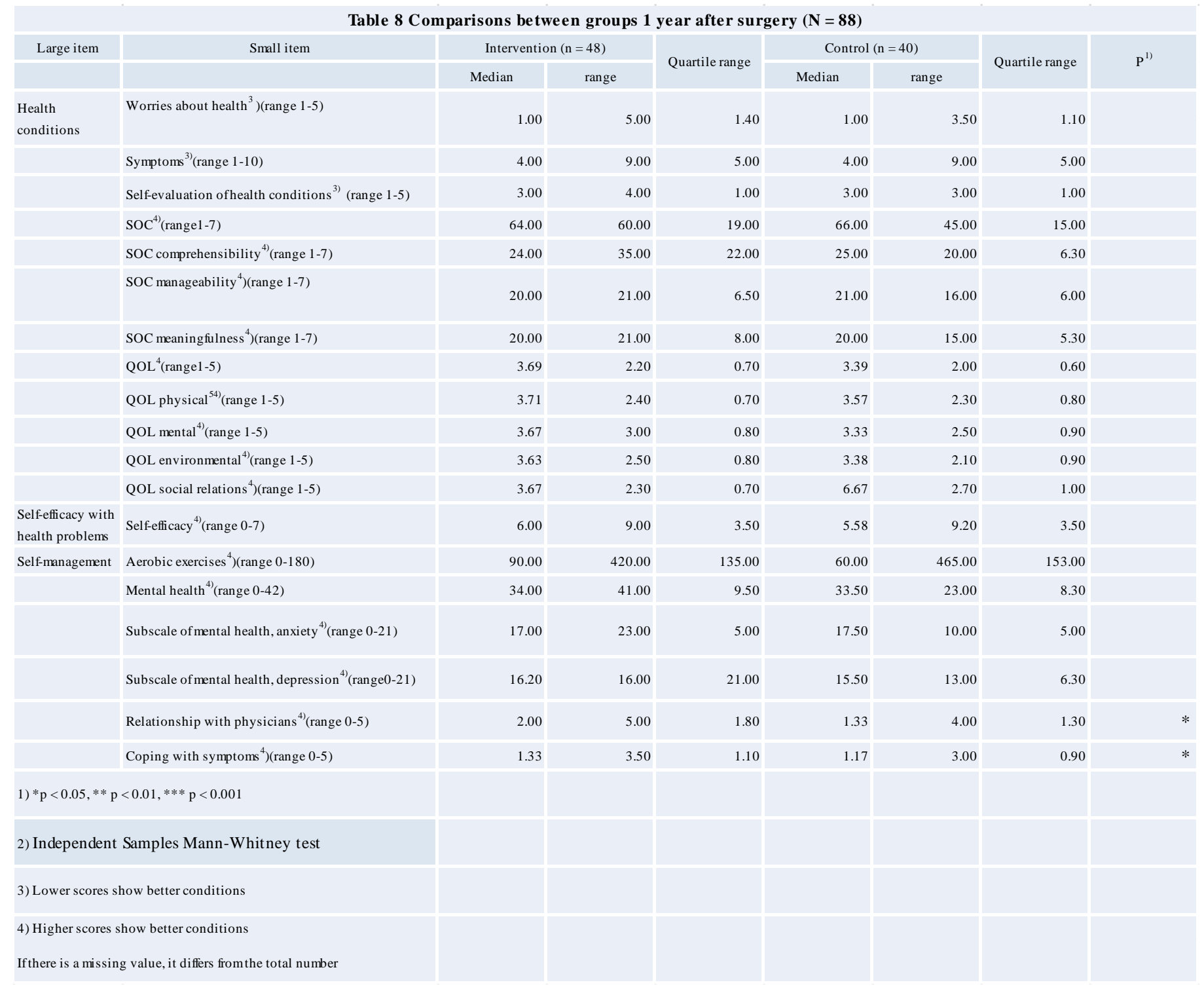

\section{DISCUSSION}

\section{A. Evaluation of population randomization}

We conducted a randomized controlled trial to examine the effectiveness of the intervention program, which promotes selfmanagement to prevent lymphedema after gynecological cancer surgery, at 12 months after gynecological cancer surgical intervention. We used envelopes that contained an identifying card with the name of either group to randomly assign the participants to the groups. The envelopes and cards were prepared by a researcher who was not involved in the group assignment. As a result, there were no differences in the groups except the response to the employment question (Table 1). There was no problem in the randomization.

\section{B. Evaluation of population randomization}

Self-management comprises the following activities for patients: "sign management (monitoring the condition at home)", "symptom management (dealing with symptoms in the everyday life)", and "stress management (getting along with developed stress)". Patients with chronic diseases have to incorporate the treatment in their life and adjust to a life different from the ordinary (so far experienced) [11] [9].

As a result of conducting self-management programs for patients with chronic diseases, self-efficacy against health problems and coping behaviors to symptoms have improved [16]. As the sign management, the participants in this study measured the femoral circumferences and body weight weekly up to 6 months after surgery, and also at 12 months. 


\begin{tabular}{|c|c|c|c|c|c|}
\hline & \multirow{2}{*}{$\begin{array}{l}\text { Partial } \\
\text { regression } \\
\text { coefficient }\end{array}$} & \multirow{2}{*}{ p } & \multirow{2}{*}{ OR } & \multicolumn{2}{|c|}{$95 \% \mathrm{CI}(\mathrm{OR})$} \\
\hline & & & & Lower & Upper \\
\hline $\begin{array}{l}\text { Group } \\
\text { (intervention or } \\
\text { control) }\end{array}$ & 1.495 & 0.009 & 4.456 & 1.451 & 13.697 \\
\hline $\begin{array}{l}\text { Aerobic } \\
\text { exercises }\end{array}$ & 0.012 & 0.025 & 1.012 & 1.002 & 1.023 \\
\hline Self-efficacy & -0.305 & 0.031 & 0.737 & 0.559 & 0.972 \\
\hline \multicolumn{6}{|c|}{ Model chi-square test $\quad \mathrm{p}<0.05$} \\
\hline $\begin{array}{l}\text { Predictive value } \\
\text { Odds ratio }\end{array}$ & \multicolumn{5}{|c|}{$68.2 \%$, SD: Standard devia tion, CI: Confidence interva1, OR: } \\
\hline
\end{tabular}

They also recorded the presence or absence of edema on a record sheet. Some participants requested us to provide additional record sheets because they wished to continue the recording regularly after the study period. This suggests that the sign management had become established among these gynecologic cancer patients following the surgery.

As the purpose of the symptom management, we explained about the causes and prevention methods of lymphedema after gynecological cancer surgery using an originally created booklet. As the participating hospitals were also giving the patients similar instruction, our explanation was a repetition, but we were able to know the understanding of the study participants. Some participants expressed their opinions as: "I will forget if I hear a lot of things at one time" and "I would like to listen to important things many times" [17]. This suggests that repeated explanations helped patients to understand the situation and issues about lymphedema more fully. A previous study has reported that patients think that there are few consultation opportunities in the outpatient visits, and that they want opportunities to ask questions and talk about worries in their everyday life [9]. For this reason, we provided monthly telephone health instruction for 6 months after the surgery. It can be inferred that health instruction by telephone helped patients to conduct stress management by solving problems in everyday life.

\section{Evaluation of the effect on prevention of lymphedema}

In a previous study the incidence of lymphedema in the intervention group 6 months after surgery was significantly lower than in the control group [9]. However, at 12 months after surgery, there was no difference in the incidence in the two groups. The reason may be that temporary lymphedema after gynecological cancer surgery often occurs about 2.6 months after surgery and chronic lymphedema around 9.7 months after surgery [18]. It is commonly assumed that lymphatic vessels damaged by the surgery are regenerated at 12 months after surgery and that lymph reflux is improved, although there may be individual differences.

Further, it was found that the participants regularly observed engaging in the sign management including the measurements of femoral circumferences and body weight, and observation of the lower limbs. It is reported that weight control and exercise therapy are effective in prevention of lymphedema [19]. In this study the right and left femoral circumferences and body weight values were significantly smaller in the intervention group than in the control group. This result suggests that the study participants had become aware of the risk of developing lymphedema, and had changed their behaviors in everyday life.

Differences in circumference are often used as a diagnostic tool for lymphedema. In the case of the lower limbs, it is recommended to measure ten parts: the roots of the right and left legs, $10 \mathrm{~cm}$ above the knees, $5 \mathrm{~cm}$ below the knees, ankles, and the circumference of the instep of the feet [20]. However, we assume that just the measuring of the femoral circumferences is effective to indicate developing lymphedema because symptoms of lymphedema appear around the trunk. Also, reducing the number of places measured will lead to reduce the burden on patients, contributing to an increase in the number of patients who conduct the self-management.

For the diagnosis of lymphedema of the upper limbs, the difference between left and right was examined. However, the determination of the left and right differences may not be a valid criterion because lymphedema may develop in both lower limbs. In this study, we compared the circumferences before discharge and 12 months after the surgery, longitudinally. Mild lymphedema is defined as a 10 to $20 \mathrm{~mm}$ increase in any part, and severe cases are defined as $20 \mathrm{~mm}$ or larger increases in any part of the body [20]. Therefore, in this study, assuming that the patients whose right side circumferences increased by more than $2 \mathrm{~cm}$ to be patients with lymphedema, we performed a multiple logistic regression analysis. The results suggested the following particulars to be factors influencing the increase in the right femoral circumference by more than $2 \mathrm{~cm}$ : groups (intervention and control), aerobic exercise, and self-efficacy. Compared to the intervention group, 4.46 times more patients in the control group had increases larger than $2 \mathrm{~cm}$ in the right femoral circumference. These findings, overall, suggest that the intervention program to promote self-management to prevent lymphedema development after gynecological cancer surgery is effective at 12 months after the surgery.

\section{CONCLUSIONS}

We conducted a randomized controlled trial to examine the effectiveness of an intervention program, which promotes (encourages) self-management to prevent lymphedema development after gynecological cancer surgery at 12 months after the intervention. There was no statistically significant difference in the incidence of lymphedema at 12 months after surgery in the intervention and control groups. However, the right and left femoral circumferences and body weight were significantly lower in the intervention group than in the control. As diagnostic criteria for lymphedema, an increase in the femoral circumference by more than $2 \mathrm{~cm}$ is used; we think it is proper to use the measurement of femoral circumference as an index for intervention effectiveness. Because 4.46 times more patients in the control group had increases in the right femoral circumference by more than $2 \mathrm{~cm}$, we were able to verify the effectiveness of the intervention program. 


\section{Study limitations}

The limitations of this study are the small number of participants, and that some participants dropped out due to deterioration of their physical conditions and death. In future study we wish to increase the number of participants to verify the findings.

\section{ACKNOWLEDGMENT}

We wish to thank the participating patients and staff of the participating hospitals for their cooperation and participation in the study. This study is a partial modification of a doctoral dissertation of the Graduate School of International Medical Welfare University of 2014.

\section{REFERENCES}

[1] Foundation for Promotion of Cancer Reserchi, Cancer statistics in jAPAN-2017,4.

[2] Ministry of Health, Labour and Welfare, Cancer Control Act (Gantaisaku kihonhou in Japanese), https://www.mhlw.go.jp/shingi/2007/04/d1/s0405-3a.pdf.Accessed on November 30.

[3] K. Onishi, K. Iino, T. Hiramatsu (Eds.), 2nd edition Cancer Nursing Science, Fundamentals and Practice of Cancer Nursing for Clinical Use (Gan kangogaku, rinshouni ikasu gan kangono kisoto jissen in Japanse), Novel Hilokawa, Tokyo, 2018.

[4] Foundation for Promotion of Cancer Reserchi, Cancer statistics in JAPAN-2017,26.

[5] Editorial committee for practical guidance of lymphedema medical care, Practical guidance for lymphedema medical care (Rinpa fushu shinryo jissen gaido in Japanese), Igakushoin, Tokyo, 2011.

[6] Japan Lymphoedema Study Group (ed.), 2014 Lymphoedema clinical practice guidelines (Rinpa fushu shinryo gaidorain in Japanese), Kanbara Publishing, Tokyo, pp. 2-5, 2014.

[7] T. Ohashi (Supervised). Guide for treatment of lymphedema: Treatment and patient guidance (Rinpafushu zensho, chiryo to kanjya shidou in Japanese), Helth Publishing, Tokyo, p. 21, 2012.

[8] H. Sasaki, Preventive surgery of lymphoedema of the lower limbs after gastroesophageal cancer surgery, 2011. Ministry of Health, Labor and Welfare Cancer Rehabilitation Seminar: Lymphoedema training, 2nd Basic Lecture Meeting (Basic 1A), 2011. pp. 60-70.

[9] M. Sato, "Development of intervention programs to promote selfmanagement for prevention of secondary lymphedema among gynecologic cancer surgery patients (Fujinkakei gan jyutugo kanjyano zokuhatusei rinpafushu yobouno tameno self management wo unagasu kainyu program kaihatsu in Japanese)", Doctoral dissertation, Graduate School of the International Medical Welfare University, pp. 1-27, 2014.

[10] M. Sato, "Development of intervention programs to promote self-care to prevent secondary lymphedema among patients after uterine cancer surgery (Shikyugan shujyutsugo zokuhatsusei rinpafushu niokeru selfcare kainyu program kaihatsu in Japanese)", Bulletin of Teikyo Heisei Nursing Junior College, vol. 21, pp. 5-7, 2011.

[11] F. Yasukata, S. Suzuki, and S. Yoshida, Nursing Grafica, Adult Nursing Science 4, Self-management (Nursing gurafika seijin kangogaku 4, serufu management in Japanese), Medica Publishing, Osaka, p. 17, 2013.

[12] K. R. Lorig, D. Sobel, and V. Gonzalez, Japan Society for Chronic Disease Self Management (Ed.), F. Kondo (Trans.) "Self-management of chronic diseases, living a health life with chronic conditions (Byokito tomoni ikiru, mansei shikkanno self-management in Japanese)", Japanese Nursing Association Publishing Company, 2008.

[13] M. Sato, A. and Muraoka, "Factors influencing lymphedema onset of gynecologyc cancer patients -Evaluation of the effectiveness of an intervention program to promote self-management of lymphedema prevention-",6th Annual International Conference on Worldwide Nursing PROCEEDINGS,128-135, 2018.
[14] Stanford Patient Education Research Center Stanford University School of Medicine. Chronic Disease Self-Management Program questionnaire code http://patienteducation.stanford.edu/research/cdcodeBook.pdf. Accessed on September 12, 2017.

[15] Y. Yamazaki, Y. Togari, and J. Sakano, "Coping with stress SOC (Stress taisho nouryoku SOC in Japanese)", Tokyo: Yushindou Koubunsha, Publishing, 2008.

[16] Y. Yonekura, "Effect of the chronic disease self-management programs in Japan, evaluation by non-randamized comparative trials using the adjustment method by likelihood score (Nihonni okeru self management puroguramuno koukano himusakuika hikakushikenniyorukento - keikou sukoaniyoru chouseihouwo mochiite in Japanese)", Report of progject of Ministry of Health, Labour and Welfare, 2009, pp. 57-60.

[17] M. Sato, R, Sato, and T. Adachi, "Ethical issues related to the life support of postoperative gynecological cancers: Consideration from the contents of the post-discharge telephone consultation (Fujinka gan shujyutsugo kanjyano seikatsu shien ni kakaru rinriteki kadai: taiingono denwa Soudan naiyou karano kousatsu in Japanese)", Journal of Japan Nursing Ethics Association, vol. 8(1), pp. 16-24, 2016.

[18] T. Ohashi (Supervised). Guide for treatment of lymphedema: Treatment and patient guidance (Rinpafushu zensho, chiryo to kanjya shidou in Japanese), Helth Publishing, Tokyo, pp. 44-51, 2012.

[19] Japan Lymphedema Study Group ed. "2014 Lymphedema clinical practice guidelines (2014nen, rinpafushu shinryo guideline in Japanese)", Kanehara \& Co., LTD, Tokyo, pp. 2-5, 2014.

[20] K. Kitamura, Project commissioned by Ministry of Health, Labor and Welfare in 2011, "Cancer rehabilitation seminar - Lymphedema training (Ganno rehabilitation seminar, rinpafushu kensyu in Japanese)", 2011 2nd Basic Lecture Meeting, pp, 18-21, 2011.

\section{AUTHOR}

Mayumi Sato:

I belong to a graduate school of nursing, specializing in oncology nursing and adult nursing. I have been engaging in research into how to encourage self-management of prevention of lymphedema in gynecologic cancer patients for 12 years. 